\title{
The Role of Pulmonary Rehabilitation in Pulmonary Tuberculosis and Pneumothorax on Functional Activity: a Case Report
}

\author{
Rachmawati Samiah, Ridwan Mochammad, Nugroho Eko, Rahma Erinda, Ainurridlo Virginia
}

\begin{abstract}
Exertional dyspnea is among the most frequently experienced symptoms of pulmonary disease and leads to physical disability and functional impairment. Secondary pneumothorax is one of pulmonary tuberculosis (TB) complication and also life threatening. Pulmonary rehabilitation is proven effective for decreasing exertional dyspnea and improving functional activity. The goal is to improve the inspiration capacity. A 24-years-old female with pulmonary tuberculosis on OAT and left pneumothorax with shortness of breath (SOB). She came first with bedridden (METS 1), pulmonary function, exertional dyspnea with Borg Scale (9), chest expansion $1 \mathrm{~cm}$, single-breath counting (SBC) test $17 \mathrm{~s}$, SpO2 95\%, BI 30. The pulmonary rehabilitation programs were deep breathing, chest expansion exercise and cardiorespiratory endurance training using ergocycle. After 1 week got pulmonary rehabilitation there were improvement of $\mathrm{SOB}$, Borg Scale, chest expansion, SBC test, and Barthel Index. Patient came to hospital with wheelchair and standing with parallel bar (METS 1,2). The Borg Scale was improved (8), chest expansion was improve to 1,2 cm, SBC test was improved to $20 \mathrm{~s}$ and BI 60. After 3-week, patient were undergo 6-MWT (120 m, METS 2,76) with Borg Scale 7, chest expansion $2 \mathrm{~cm}$, SBC test was $23 \mathrm{~s}$, and BI 85. Pulmonary rehabilitation programs is great to improve respiratory function \& functional activity, even in the condition of patients with pneumothorax that have not improved in outpatient with SOB dt. Pulmonary Tuberculosis and Pneumothorax.
\end{abstract}

Keywords: Pulmonary rehabiltation, lung tuberculosis, pneumothorax.

\section{INTRODUCTION}

Exertional dyspnea is among the most frequently experienced symptoms of pulmonary disease and leads to physical disability and functional impairment. Pneumothorax is a condition in which there is air in the pleural cavity. Pneumothorax is divided into two, spontaneous that occurs without trauma or other causes, and traumatic that occurs due to direct or indirect trauma to the chest, including iatrogenic pneumothorax. ${ }^{1}$ Around the 19th

Revised Manuscript Received on January 2, 2020.

* Correspondence Author

Rachmawati Samiah*, Department of Physical Medicine and Rehabilitation, Medical Faculty Brawijaya University, dr. Saiful Anwar Hospital, Malang, Indonesia. Email:

Ridwan Mochammad, Department of Physical Medicine and Rehabilitation, Medical Faculty Brawijaya University, dr. Saiful Anwar Hospital, Malang, Indonesia. Email: jari2121@gmail.com

Nugroho Eko, Department of Physical Medicine and Rehabilitation, Faculty of Medical Faculty Brawijaya University, dr. Saiful Anwar Hospital, Malang, Indonesia. Email: century it was found that TB was one of the main causes of pneumothorax. ${ }^{2}$ Spontaneous pneumothorax is divided into primary pneumothorax and secondary pneumothorax. Secondary pneumothorax is one of pulmonary tuberculosis (TB) complication and also life threatening. ${ }^{3}$

Pulmonary rehabilitation is a therapy given to patients who have lung disease and the patient's family. The goals of pulmonary rehabilitation are improvement in cardiopulmonary function, prevention and treatment of complications, increased understanding of the disease, increased patient responsibility, for self-care and compliance with medical treatment, improvement in quality of life, capacity for activities of daily living, and return to work. Interventions can include exercise, respiratory muscle rest and support, education, emotional support, oxygen, airway secretion clearance, and promoting compliance with medical care. These goals are appropriate for any patients with diminished respiratory reserve whether due to obstructive or intrinsic pulmonary diseases (oxygenation impairment) or neuromuscular weakness (ventilatory impairment). ${ }^{4}$ Pulmonary rehabilitation has been found to be a safe, effective, and beneficial program in controlling breathing and cough, reducing dyspnea, improving patient pulmonary function capacities and quality of life. ${ }^{5,6}$

Study conducted by Cheng found that pulmonary rehabilitation had good effect for autonomic function, quality of life, and also exercise capacity. ${ }^{7}$ A number of participants were included in the rehabilitation program for 12 weeks, with 2 sessions per week. Before give rehabilitation program, each participant was given training \& education about breathing exercise, proper use of medications and self management skills. After that, for increasing endurance on lower extremity, patient must do ergocycle. Another study from Riario-Sforza proved that out-patient pulmonary rehabilitation improving patient exercise tolerance in patient with mild COPD. Physical exercise, respiratory muscle training, upper extremity and trunk exercise are pulmonary rehabilitation program that we can give. The improvement can be checked by the 6-minute walking test which shown an increasing in walking distance.

\section{CASE REPORT}

A 24-years-old female with pulmonary tuberculosis on OAT and left pneumothorax with shortness of breath (SOB). At the first visit she came with bedridden (METS 1), 
The Role of Pulmonary Rehabilitation in Pulmonary Tuberculosis and Pneumothorax on Functional Activity: a Case Report

pulmonary function, exertional dyspnea with Borg Scale (9); chest expansion $1 \mathrm{~cm}$; single-breath counting (SBC) test 17 s; $\mathrm{SpO} 2$ 95\%, BI 30; CXR results show pneumothorax sinistra and military TB.

The outpatient pulmonary rehabilitation program consisting of deep breathing exercise, chest expansion exercise and cardiorespiratory endurance training for once a week under supervision and home-based pulmonary rehabilitation. After 1 week got pulmonary rehabilitation program there were improvement of SOB, Borg Scale, chest expansion, SBC test, and Barthel Index. Patient came to hospital with wheelchair and standing with parallel bar (METS 1,2). The Borg Scale was improved to 8, chest expansion was improve to $1,2 \mathrm{~cm}, \mathrm{SBC}$ test was improve to $20 \mathrm{~s}$ and BI 60. After 3 week, patient were undergo 6-MWT (120 m, METS 2,76) with Borg Scale 7, chest expansion 2 $\mathrm{cm}, \mathrm{SBC}$ test was $23 \mathrm{~s}$, and BI 85 .

\section{RESULT AND DISCUSSION}

An important problem for patients with interstitial lung disease is severe hypoxemia that requires high flow of oxygen with exercise to maintain adequate saturation for activity. It is important in this group to avoid the occurrence of chronic hypoxemia to prevent secondary pulmonary hypertension because the coexistence of interstitial lung disease and pulmonary hypertension can lead to very reduced life expectancy. The intensity of exercise is often limited to patients with interstitial lung disease due to oxygenation rather than dyspnea. ${ }^{9}$

Pulmonary rehabilitation in this case has been found to have beneficial effects for pneumothorax patients in reducing the symptoms of dyspnea, improve pulmonary function and quality of patient health. The pulmonary rehabilitation program that we carry out, in accordance with the recommendations of the British Thoracic Society guidelines. ${ }^{10}$

A home based pulmonary rehabilitation by Grobois, et al show that home exercise program that he gave for unselected COPD not only had effect in the short term, but this effectiveness also can exceed until the medium term (6 months) and the long term (12 months). Home-based PR have beneficial for outpatient management include activities, such as exercise conditioning, therapeutic education, and self-management. ${ }^{11}$ Corresponding to our study, the aims of pulmonary rehabilitation in this study is to breathing control, strengthening the respiratory muscles, improving endurance and quality of life (increase of Barthel Index).

\begin{tabular}{|ccc} 
TABLE 1: RESULT OF PULMONARY FUNCTION TEST AND \\
QUALITY OF LIFE ASSESSMENT BEFORE AND AFTER \\
PULMONARY REHABILITATION PROGRAM IN A PATIENT \\
WITH PULMONARY TB \& PNEUMOTHORAX.
\end{tabular}

Figure 1. Chest Expansion \& Count Breathlessness Test

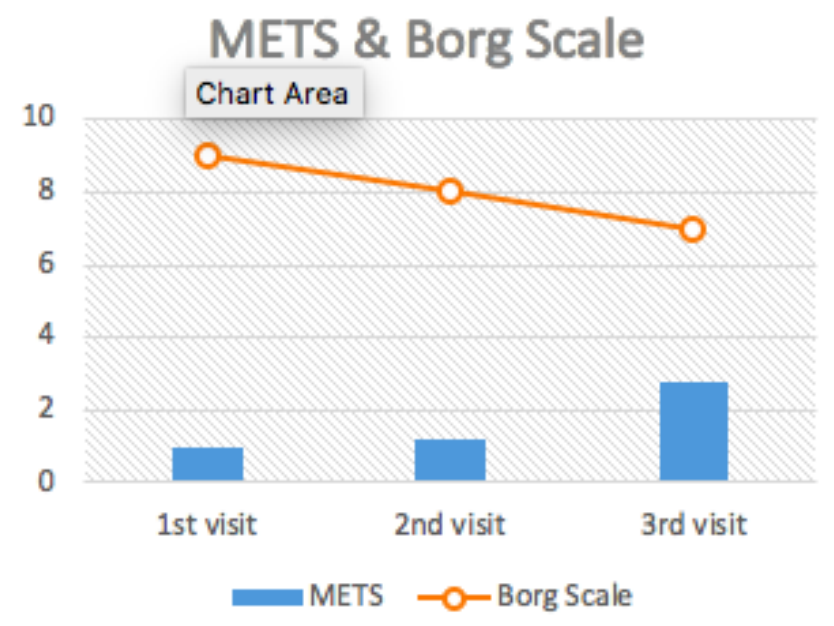

Figure 2. METS and Borg Scale

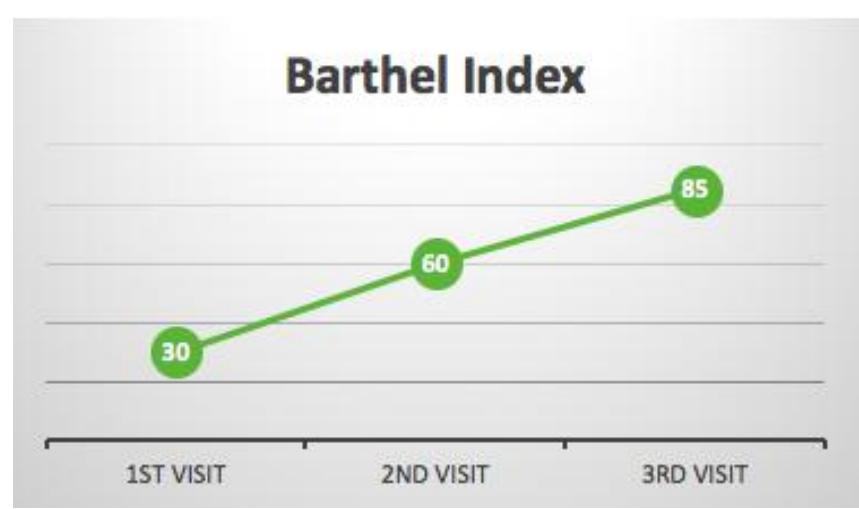

Figure 3. Barthel Index

\section{CONCLUSION}

Pulmonary rehabilitation programs in this case aims to breathing control, strengthen respiratory muscles, increase endurance that can lead to improve patient's pulmonary function capacities and quality of life. 


\section{ACKNOWLEDGMENT}

The authors would thanks to all staff Department of Physical Medicine and Rehabilitation Medical Faculty Brawijaya University,

dr. Saiful Anwar Hospital to give support to authors for treating this pneumothorax patient.

\section{REFERENCES}

1. Light RW, Gary LYC. Pneumothorax, Chylothorax, Hemothorax, and Fibrothorax. In: Robert J Mason et al, editor. Textbook of Respiratory Medicine. 5th ed. Philadelphia: Saunders Elsevier; 2010. p. 1764-87

2. Slobodan M, Spasic M, Milosevic B, 2015. Pneumothorax: Diagnosis and Treatment.
Sanamed. https://scindeks-clanci.ceon.rs/data/pdf/1452-662X/2015/1452-662X1503 221M.pdf. Accessed 01 November 2019.

3. Arshad H, 2016. Acute Pneumothorax. Wolters Kluwer Health, Inc. Vol. 39, No. 2, pp. 176-189

4. DeLisa J, et al. (2010). DeLisa's Physical Medicine \& Rehabilitation $5^{\text {th }}$ Edition Vol I. Lippincott Williams \& Wilkins, 42: 1099-1108.

5. Lacasse Y, Goldstein R, Lasserson TJ, Martin S. Pulmonary rehabilitation for chronic obstructive pulmonary disease. Cochrane Database Syst Rev. 2006;(4):CD003793.

6. Jacome C, Marques A. Impact of pulmonary rehabilitation in patients with mild COPD. Respir Care. 2014 May; 59(10):1-6.

7. Cheng Tsung-Shih, Wu Yao-Kuang, et al. Pulmonary rehabilitation improves heart rate variability at peakexercise, exercise capacity and health-related quality of life inchronic obstructive pulmonary disease. Elsevier. 2014 March; 43 (2014) 249e255.

8. Riario-Sforza GG, Incorvaia C, Paterniti F, Pessina L, Caligiuri R, Pravettoni $\mathrm{C}$, et al. Effects of pulmonary rehabilitation on exercise capacity in patients with COPD: a number needed to treat study. Int J Chron Obstruct Pulmon Dis. 2009;4:315-319.

9. Cifu X, et al. (2011) Braddom's Physical Medicine \& Rehabilitation $5^{\text {th }}$ Edition. Elsevier.

10. Bolton CE, et al. Thorax 2013;68:ii1-ii30

11. Grobois, et al. Long-term evaluation of home-based pulmonary rehabilitation in patients with COPD. International Journal of COPD. 2015: 10 2037-2044

\section{AUTHORS PROFILE}

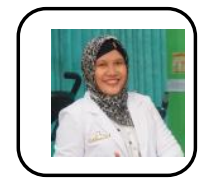

Samiah Rachmawati, MD, SpKFR is a Physiatrist who received her medical doctor on Hang Tuah University Surabaya and become a physiatrist on Airlangga University Surabaya. Now she work as a staff on dr. Saiful Anwar Hospital Malang. She is an active member of ISPRM (International Society of Physical \& Rehabilitation Medicine) and PERDOSRI (Perhimpunan Dokter Spesialis Rehabilitasi Medik Indonesia)

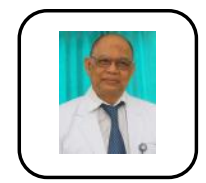

Mochammad Ridwan, MD, $\operatorname{SpKFR(K)}$ is a Physiatrist who received his medical doctor on Airlangga University Surabaya and become a physiatrist on Airlangga University Surabaya. He also received consultant for musculoskeletal from PM\&R Kolegium Indonesia. Now he work as a staff on dr. Saiful Anwar Hospital Malang. He is an active member of ISPRM (International Society of Physical \& Rehabilitation Medicine), Indonesian Pain Society, and PERDOSRI (Perhimpunan Dokter Spesialis Rehabilitasi Medik Indonesia).

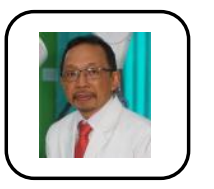

Eko Nugroho, MD, SpKFR is a Physiatrist who received his medical doctor on Airlangga University Surabaya and become a physiatrist on Airlangga University Surabaya Now he work as a staff on dr. Saiful Anwar Hospital Malang. He had undergone a fellowship program for Orthopedic Rehabilitation on Nobuhara University Japan. He is an active member of ISPRM (International Society of Physical \& Rehabilitation Medicine) and PERDOSRI (Perhimpunan Dokter Spesialis Rehabilitasi Medik Indonesia). 